\title{
Implicações práticas das Missões de Paz Híbridas: um estudo comparado entre UNAMID e UNAMIR
}

Practical implications of Hybrid Peace Missions: a comparative study between UNAMID and UNAMIR

Rhaíssa Pagot ${ }^{1}$

Kelly Patrícia Ernst ${ }^{2}$

DOI: 10.5752/P.1809-6182.2019v16.n1.p18

Recebido em: 03 de novembro de 2018 Aceito em: 23 de março de 2018

\section{Resumo}

A demora da ONU em tratar o genocídio em Ruanda (1993) refletiu no massacre em Darfur (2004). Nesse último caso, foi criada uma missão de paz híbrida com a União Africana. Partindo da comparação entre elas, refuta-se que a condução da missáo seja afetada somente pela sua composiçâo.

Palavras-chave: UNAMIR, UNAMID, missão de paz híbrida.

\section{Abstract}

The long time that United Nations took to consider the conflict in Ruanda (1993) as genocide reflected in the situation in Darfur (2004). In this case, it was created a hybrid peace operation with African Union. From the comparison, we refuted that the conduct of the mission is affected only by its composition.

Keywords: UNAMIR, UNAMID, hybrid peace mission.

\footnotetext{
1 Doutoranda em Ciência Política pela Universidade Federal do Rio Grande do Sul (UFRGS). Mestra em Relaçóes Internacionais pela Universidade Federal de Santa Catarina (UFSC). Bacharela em Relaçôes Internacionais pela Universidade de Santa Cruz do Sul (UNISC). Pesquisadora do Núcleo Interdisciplinar de Estudos da Mulher e Gênero (NIEM/UFRGS). Porto Alegre, Brasil. ORCID: 0000-0002-2736-6913. (iD

2 Mestra em Relaçôes Internacionais pela Universidade Federal de Santa Catarina (UFSC). Bacharela em Relaçóes Internacionais pela Universidade de Santa Cruz do Sul (UNISC). Novo Machado, Brasil. ORCID: 0000-0002-2767-9944. (D)
} 


\section{Introdução}

O presente estudo abordará as diferenças na missão de paz híbrida da Organização das Nações Unidas (ONU) e da União Africana (UA) em Darfur (United Nations African Union Mission in Darfur - UNAMID) em comparação com a missão com tropas apenas da ONU em Ruanda (United Nations Assistance Mission in Rwanda - UNAMIR). A escolha dessas missóes ocorreu devido às semelhanças entre os fatos que levaram à eclosão do conflito, as implicaçóes do termo genocídio, a presença de missóes de paz em ambos os casos e a tentativa falha de encaminhar um acordo de paz por parte da Organização da Unidade Africana (OUA) no caso ruandês e por parte da UA no caso sudanês.

A partir de um breve histórico dessas missões de paz será possível estabelecer os debates que culminaram na decisão de envolver organizaçóes regionais na realização de algumas missóes, tornando-as híbridas. Considerando a teoria acerca das mudanças no pós-Guerra Fria das missóes de paz em geral e da criação das missōes híbridas, se entenderá qual a intenção de unir os esforços da ONU com os de outras organizaçóes, como a UA. Apesar da presença da OUA nas negociaçôes relativas à Ruanda, esta ainda era muito tímida e náo havia uma parceria institucionalizada com a ONU, o que aconteceu em Darfur.

O estudo comparativo entre os casos apresentados incluirá informaçôes como a composição das missões, orçamentos, fatalidades, sucessos e fracassos. Assim, busca-se identificar se existem mudanças na condução e em campo e maior agilidade na soluçâo do conflito devido ao suposto caráter africano conferido à missão híbrida em Darfur, ressaltando as diferenças e semelhanças entre ela e a missão exclusiva da ONU em Ruanda.

\section{Evolução das Missões de Paz}

O desenvolvimento das operaçóes de paz ocorreu no período da Guerra Fria, como uma resposta parcial à falha do mecanismo de segurança coletiva da ONU, a fim de auxiliar no controle e resolução de conflitos armados e, portanto, na manutenção da paz e segurança internacional (REZENDE, 2012), a partir de três princípios norteadores - consentimento das partes, imparcialidade e não-uso da força. A ascensão da violência e dos conflitos intraestatais no cenário internacional pós-Guerra Fria resultou na significativa alteração do caráter dos mandatos das missóes de paz. Dessa forma, as operaçôes de paz unidimensionais são assentadas no Capítulo VI da Carta da ONU, com objetivo de apoiar o cessar-fogo e construir acordos de paz (POTI, 2014).

Já as operações de paz multidimensionais possuem mandatos complexos, assentados no Capítulo VII da Carta da ONU, o que amplia seu foco para esforços de manutenção da paz e, até mesmo, atividades de construção da paz. Por isso, essas missões são compostas por contingente militar, policial e civil, e visam a promoção da coordenação no nível nacional entre a ONU e outros atores internacionais. As principais tarefas desempenhadas estão relacionadas à proteção de civis, promoção de direitos humanos e igualdade de gênero, bem como à facilitação de processos políticos, eleitorais e judiciários. Dentro do escopo multidimensional, existem as operações de imposição da paz e as operaçóes de paz robustas. Ambos os tipos possuem permissão para o uso da força, mas com diferenças relevantes: (1) necessidade de autorização do Conselho de Segurança das Nações Unidas (CSNU) para o emprego da força; (2) nas operaçóes de imposição da paz o uso da força é empregado no nível estratégico (âmbito decisório), sem o consentimento das partes beligerantes; e (3) 
nas operaçốes de paz robustas emprega-se a força no nível tático (tarefas desempenhadas em campo), com o consentimento do país anfitrião. Além disso, as operaçôes de imposição da paz são implementadas por organizações regionais, e não pelas tropas da ONU - que apenas se engaja diretamente nas operaçóes de paz robustas (POTI, 2014).

Ademais, o fim da lógica bipolar trouxe o término da paralisia do Conselho de Segurança das Nações Unidas, por meio do aumento significativo de resoluçôes, efetivo militar, orçamento e número de missões autorizadas, com foco no continente africano (OTHIENO; SAMASUWO, 2007). Conforme sugere Hehir (2008), houve o crescente interesse no debate e na ação acerca das intervençôes humanitárias no pós-Guerra Fria, delineadas de acordo com a visão humanitária do poder hegemônico: os Estados Unidos da América (EUA). Assim, as intervenções humanitárias sem implicações políticas ou militares são ilusórias, e há controvérsias acerca de suas definiçôes e aplicaçóes ocidentais. Sem o veto soviético, as ameaças aos direitos humanos se tornaram mais consensuais no CSNU, facilitando a aplicação do regime humanitário global em casos como genocídio e crimes contra a humanidade (HEHIR, 2008).

Entretanto, o genocídio já era considerado uma grave violação dos direitos humanos antes disso. Segundo a Convenção para Prevenção e Punição do Crime do Genocídio, adotada pela Assembleia Geral das Naçóes Unidas (AGNU) em 9 de dezembro de 1948, genocídio significa qualquer um dos seguintes atos cometidos com a intenção de destruir, no todo ou em parte, um grupo nacional, étnico, racial ou religioso nacional tais como: (a) assassinato de membros do grupo; (b) dano grave à integridade física ou mental de membros do grupo; (c) submissão intencional do grupo a condiçôes de existência que lhe ocasionem a destruição física total ou parcial; (d) Medidas destinadas a impedir os nascimen- tos no seio do grupo; (e) transferência forçada de crianças do grupo para outro grupo (UNGA, 1951, p. 280).

Makinda e Okumu (2007) apontam a multiplicidade, interconexão e complexidade das velhas e novas ameaças de segurança como motivos para a difícil efetividade das missões de paz da ONU no continente africano. Diante disso, a ONU vem alterando a natureza de suas missóes, e um exemplo é a cooperação com outras organizações internacionais, que culminam na formação de missóes de paz híbridas. Conforme Kenkel (2013), as missóes híbridas empregam contingente militar e policial sob comando misto, isto é, tropas da ONU e de outras organizaçôes globais, continentais e regionais atuam de forma simultânea, sob comandos separados e mandatos distintos.

Uma missão híbrida enquadra-se no escopo multidimensional e deve satisfazer algumas características, segundo Aboagye (2007, p. 2): a) se tratar de uma operação multinacional em uma área de responsabilidade operacional específica; b) ser conduzida por forças de diferentes organizaçóes e/ou Estados, com mandatos próprios; c) estar sob um acordo que lhe confira status de Força ou Missão e sob acordo com a nação anfitriā; d) possuir distintas regras de compromisso e funçóes/tarefas; e) cada força estar sob o comando e controle da autoridade de seu respectivo mandato e permanecer com sua identidade durante a operação; f) manter a provisão para a coordenação das operações em sua área de responsabilidade operacional; g) com o intuito de alcançar seus objetivos, as forças devem contribuir juntas para gerenciar e solucionar o conflito das perspectivas política e militar.

Dito isso, o pós-Guerra Fria acentuou o emprego de missóes multidimensionais, visto que $\mathrm{My}$ int-U e Scott (2007) apontam que os gastos com missões de paz aumentaram de US\$ 266 milhões em 1988 para US\$ 3,1 bilhóes em 1993, demons- 
trando a importância que a ONU estabeleceu para a paz e segurança. Ademais, as potências ocidentais iniciaram a "guerra ao terror" após os atentados terroristas ao World Trade Center, em 11 de setembro de 2001, o que possibilitou maior participação em missões de paz de países em desenvolvimento (Índia, Bangladesh, Paquistão, entre outros), devido sua neutralidade e baixa ameaça aos membros permanentes do CSNU (GOWAN; JOHNSTONE, 2007), com ênfase na África devido ao fim da lógica bipolar, que gerou excedente de armamentos e diminuição de investimentos naquele continente, intensificando conflitos latentes; e a proeminência do ganês Kofi Annan no âmbito da ONU (LOPES, 2007). Isso resultou no incentivo por parte da ONU às missões híbridas na África, conferindo à União Africana e às comunidades econômicas regionais relevância maior, sob o discurso de autonomia africana na resoluçấo de seus próprios problemas (GOWAN; JOHNSTONE, 2007).

A OUA e outras organizações regionais africanas, como a Economic Community of West African States (ECOWAS) e a Southern African Development Community (SADC), participavam de esforços de entender a importância da cultura e política locais no alcance da paz desde o início da década de 1990 (HUDSON, 2005). A possibilidade de missóes de paz híbridas com uma organização continental africana só existiu a partir de 2002, com a substituição definitiva da OUA pela UA, já que a primeira não admitia a intervenção nos seus Estados membros, enquanto a União Africana trouxe a cláusula de intervenção em sua própria carta constitutiva (AFRICAN UNION, 2000). Destaca-se que o genocídio em Ruanda foi parcialmente responsável por essa mudança constitutiva da UA, e também fez a ONU repensar e aceitar a cooperação com organizações regionais e continentais para garantir maior eficiência e rapidez. Os prós do hibridismo de fato seriam a proxi- midade geográfica, social e de outras dinâmicas do conflito. Os contras seriam a redução da imparcialidade e da credibilidade justamente por tais proximidades. É uma tentativa de manter a questâo a nível local. Todavia,

A virada local deslocou a literatura para uma visão muito mais positiva dessas adaptaçôes locais e suas legitimidades como fontes de poder, até mesmo uma noçấo um tanto romântica de ordens locais não-estatais como fontes inerentemente positivas de modelos de governança (WALLIS et al, 2018, p. 39).

Em contextos africanos, tal colocação aponta para a reflexão acerca de que tipo de paz e segurança são almejadas. $\mathrm{O}$ colonialismo e a escravidão se perpetuaram com o auxílio ou, no mínimo, com a complacência das elites locais. Sendo assim, quem são os envolvidos nas missões híbridas? Quais as diferenças na condução dessas operaçôes?

\section{O Genocídio em Ruanda: a Ineficiência da UNAMIR}

Uma elite Tutsi foi escolhida pelos colonizadores belgas para auxiliá-los a administrar a colônia Ruanda, o que incitou ódio entre os Tutsi e os Hutu. Em 1973 ascendeu ao poder Habyarimana, que dizia querer eliminar a discriminação étnica. McQueen (2005) aponta que nos anos 1990 ainda existiam cerca de 700 mil refugiados ruandeses Tutsi, reforçando a hostilidade do governo a essa etnia. Nesse período, o Rwandan Patriotic Front (RPF) e o seu braço militar, o Rwandan Patriotic Army (RPA), deram suporte aos refugiados. O presidente Habyarimana investiu contra os rebeldes e, consequentemente, contra os Tutsi, sendo necessária a intervenção da França, da Bélgica e do Zaire. Devido a um cessar-fogo acordado em julho de 1992, 50 membros do Neutral Military Observer Group I (NMOG I), mobilizados pela OUA, desembarcaram em Ruanda (MCQUEEN, 2005). 
Em 22 de junho de 1993 a ONU autorizou a United Nations Observer Mission Uganda-Rwanda (UNOMUR) para observar a fronteira entre Uganda e Ruanda. O RPF convenceu o governo ruandês a assinar os Acordos de Paz de Arusha, na Tanzânia, em agosto de 1993, resolvendo a questão dos refugiados, e encerrando a missão em 21 de setembro de 1994 (UNSC, 1993; KUPERMAN, 2004). Para garantir o cumprimento desses acordos, o CSNU estabeleceu, em 5 de outubro de 1993, o mandato para a United Nations Assistance Mission for Rwanda (UNAMIR), baseada no Capítulo VI.

O estopim para o massacre aos Tutsi foi a acusação de autoria do atentado aos presidentes de Ruanda e do Burundi, mortos na queda de um aviāo quando voltavam de negociaçóes de paz na Tanzânia em 6 de abril de 1994. Como retaliaçấo às mortes e aos acordos assinados pelo presidente Habyarimana, extremistas Hutu assumiram o controle das forças armadas ruandesas, iniciando o genocídio (MOGHALU, 2005). Conforme Kuperman (2004), apenas na capital Kigali, na primeira semana de genocídio foram mortos mais de 20 mil civis. Estima-se que entre 500 mil e 800 mil Hutu moderados e Tutsi tenham sido mortos em Ruanda entre abril e julho de 1994. Os rebeldes Tutsi mataram cerca de 60 mil Hutu entre abril de 1994 e agosto de 1995 (KUPERMAN, 2004).

Os EUA tinham pouco interesse para intervir e a França tinha laços estreitos com o governo ruandês. Por isso, apenas em 4 de maio de 1994 o secretário geral da ONU admitiu a ocorrência de um genocídio em Ruanda, de modo que se iniciou uma intervenção mais convincente por meio da UNAMIR, encerrada em abril de 1996. Diante do caos e da morte de 10 soldados belgas da missáo em Ruanda, esta foi considerada uma das mais desastrosas missóes de paz da ONU por permitir um massacre durante a presença de tropas no território e pela demora em dizer que se tratava de um genocídio (BARROS, MORAIS, DAHER, 2008).

\section{O Conflito em Darfur e a Missão Híbrida UNAMID}

Darfur, região oeste do Sudão, foi negligenciada pelo governo central sudanês desde a colonização. A situação piorou devido à guerra civil no vizinho Chade nos anos 1980. Em 1983 começou a guerra civil sudanesa entre o governo do Sudão e os rebeldes do Sudan People's Liberation Army (SPLA). A assinatura do Protocolo de Machakos, que incluía um cessar-fogo imediato, ocorreu em 20 de julho de 2001. Apesar do acordo, o conflito se intensificou em fevereiro de 2003, quando o SLPA atacou a força armada nacional sudanesa (WAAL, 2007). Os rebeldes do Justice and Equality Movement (JEM) uniram-se ao SPLA na busca de atenção do governo árabe do Sudão para a região.

A milícia Janjaweed lutou ao lado do governo do Sudão, assassinando e estuprando milhares de civis. Bellamy (2005) defende que o genocídio no país (extermínio de africanos por árabes) era evidente: cerca de 300 mil mortes em Darfur, e mais de 1,8 milhóes de refugiados até janeiro de 2005. Diante desse cenário, a UA enviou 60 observadores militares e cerca de 300 soldados de proteção em abril de 2004, para monitorar o cumprimento de um acordo de cessar-fogo assinado pelas três partes. Logo, foi elaborado um relatório sobre a região e apresentado ao Conselho de Paz e Segurança da Uniâo Africana, em abril de 2004. A partir dele foi criada a African Union Mission in Sudan (AMIS) (AFRICAN UNION PSC, 2004).

Mesmo estando cientes das práticas do governo e da milícia, apenas em meados de 2004 a ONU afirmou que a situação em Darfur era a emergência humanitária mais séria de todo o mundo naquele momento. Surgia assim a United Nations Advance Mission in the Sudan (UNAMIS), em 11 de junho de 2004 (UNSC, 2004). O Secretário-Geral da ONU, Kofi Annan, recomendou uma missão de paz multidimensional, com mandato baseado no Capítulo VII e que 
atuasse em conjunto com a UA. Seguindo a recomendação, em 24 de março de 2005, foi criada a United Nations Mission in Sudan (UNMIS) (UNSC, 2005).

Em 31 de agosto de 2006 a UNMIS começou a operar em Darfur, articulando a transição para missão híbrida da ONU e da UA. Como previsto, a United Nations African Union Mission in Darfur (UNAMID) foi implementada a partir de 31 de julho de 2007 (UNSC, 2006; 2007). A inexperiência em missóes híbridas levou seus formuladores a se questionarem sobre alguns pontos práticos: comando, número e capacidade das tropas, mandato e financiamento (WAAL, 2007). Murithi (2008) alerta que havia muito temor por parte dos africanos de que as assimetrias entre as organizaçóes pudessem resultar em paternalismo por parte da ONU, ao invés de parceria. A missão continua ativa, sendo que o último mandato foi renovado em junho de 2017 até junho de 2019.

\section{O Caráter Africano da UNAMID em Comparação com a UNAMIR}

Segundo relatório da ONU divulgado em 2005 (UNSC, 2005), as operaçôes de paz no continente africano estão mais eficazes, auxiliando a dirimir conflitos que pareciam insolúveis. A crença da ONU na maior eficiência dos próprios africanos em buscar soluçôes demonstra que a organização confia em recursos como as missóes híbridas, nas quais os africanos têm maior participação. Um dos diferenciais desse tipo de missão é o comando, realizado apenas por africanos, que é o caso da UNAMID. Já em uma missão não-híbrida, como a UNAMIR, os cargos de comando em geral são ocupados não só por africanos. Esse discurso de privilegiar tropas e comandantes africanos em missóes híbridas aumentou a legitimidade destas devido ao caráter africano; porém, Badescu e Bergholm (2009) argumentam que a nacionalidade dos comandantes implica pouco na prática se não há um mandato claro e nem condiçôes mínimas de proteger civis.
A UNAMID, por ser uma missão híbrida, deveria suprir as falhas apontadas nas missões anteriores. A presença de tropas ruandesas, em 30 de setembro de 2014, demonstra a intenção de que seu aprendizado auxiliasse no fim do genocídio em Darfur. Aliás, o genocídio ocorreu em ambas as situações mesmo com a presença de missões de paz naqueles países. Em Ruanda, a UNAMIR diminuiu seus efetivos no auge do genocídio, em abril de 1994, alegando falta de segurança da missão após a morte de integrantes belgas (UN, 2001). No Sudão, tanto a UNMIS quanto a AMIS operavam na época do genocídio. Com isso, mostra-se a falta de capacidade das missóes de paz da ONU, e mesmo da missão da UA, de identificar e prevenir estes genocídios, e de impedir sua continuação.

Na prática, o Gráfico 1 demonstra que, a porcentagem de africanos na UNAMID em comparaçâo com a UNAMIR é praticamente a mesma. Os dados apresentados no Gráfico 1 variam muito pouco de acordo com o período. A data analisada da composição da UNAMIR foi 30 de novembro de 1994 e da UNAMID foi 30 de setembro de 2014. Embora percentualmente a África tenha participado de maneira muito similar, ressalta-se que em números absolutos há uma diferença significativa entre as missões. Isso acontece pela complexidade da situação e pelo mandato mais reforçado em Darfur. Enquanto o efetivo total da UNAMIR era de 5.522, o da UNAMID era de 16.096 (UN, 2001; 2014).

Os países que mais contribuíram com integrantes para a UNAMIR foram Gana (896), Tunísia (854) e Etiópia (805); os três africanos. Etiópia (2.575), Ruanda (2.516) e Paquistão (2.277) foram os maiores contribuintes para a UNAMID. Assim, destaca-se a Etiópia como preocupada em estabelecer a paz na África. Outros países ditos como potências africanas, como Egito e Nigéria, também cooperaram. A Nigéria enviou pessoal para as duas 
missões estudadas, 363 para a UNAMIR e 1.032 para a UNAMID. O Egito enviou apenas para a UNAMID 1.150 militares e civis. Destaca-se também a presença chinesa na operação em Darfur: 235 tropas (UN, 2001; 2017) - reflexo da progressiva participação do país no âmbito onusiano que, em 2018, foi o segundo maior contribuinte financeiro para o orçamento das operaçóes de paz e o décimo maior contribuinte de tropas (UNGA, 2015; UNP, 2018). Se um dos diferenciais da missão em Darfur deveria ser justamente a maior presença de integrantes africanos, em comparação com a missão em Ruanda, isso não se configura como uma realidade. Mesmo em anos anteriores, como 2014, 75,74\% do total de componentes da UNAMID eram do continente africano, não superando a porcentagem da UNAMIR (UN, 2014).

Kreps (2007) considera que o treinamento do pessoal da UNAMID foi um desafio, especialmente quanto à polícia civil, pois a UA nunca havia tido policiais civis em suas missóes e todo o treinamento foi realizado em apenas quatro dias, sem incluir informaçóes sobre leis locais e direitos humanos; além da dificuldade na mobilidade (250 policiais civis para apenas quatro veículos). Waal (2007) aponta que a falta de capacitação do pessoal agravou as fa- lhas da UNAMID. Essa é uma questão sensível em relação às missóes híbridas, uma vez que a capacitação geralmente é realizada pela ONU e baseada em seu conhecimento e manuais prévios, com pouco grau de adaptabilidade local (WALLIS et al, 2018).

Badescu e Bergholm (2009) acreditam que o alto nível de poder político envolvido na missão híbrida, por parte dos membros permanente do CSNU, da UA e do próprio governo sudanês, desviou o foco da missão. A UNAMID é uma operação onerosa para a ONU, custando anualmente entre 1,2 e 1,7 bilhão de dólares (UNGA, 2014). O orçamento total da UNAMIR, desde seu início, em outubro de 1993, até o fechamento dos escritórios administrativos, em junho de 1997, foi de U\$ 453 milhóes, pouco mais de um terço do orçamento estimado para a UNAMID em 2014/2015, de U\$ 1,24 bilhão (UN 2001; UNGA, 2014). Esse comparativo não considera os ajustes monetários dos mais de dez anos que separam as missóes, mas auxilia na compreensão do quão importante é uma missão ter fortes componentes políticos, o que a UNAMIR não tinha. Esse orçamento tão significativo no quadro geral na ONU é também pela missão híbrida ter seu mandato baseado no Capítulo VII.

\section{Gráfico 1 - Composição da UNAMIR e da UNAMID por continente}

UNAMIR

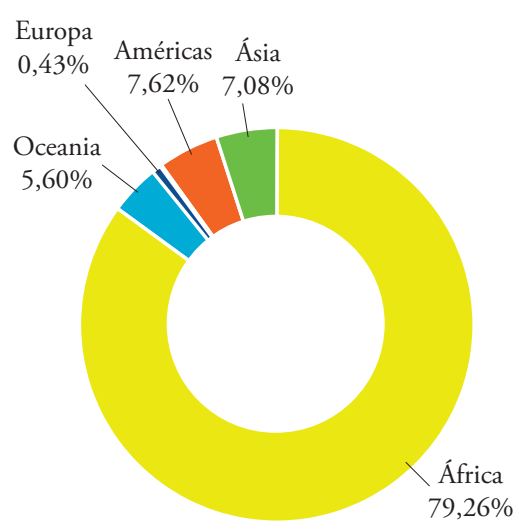

UNAMID

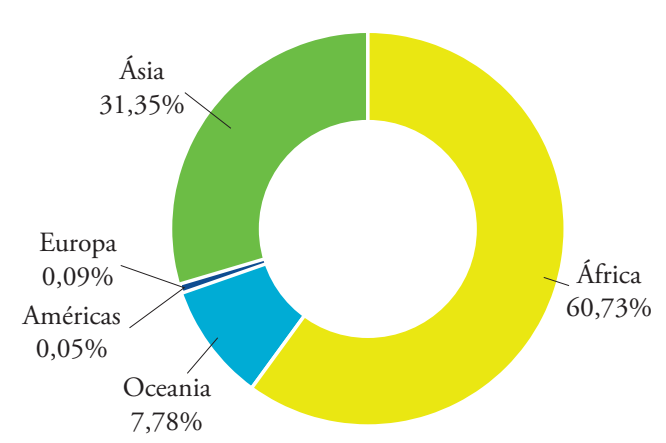

Fonte: Elaborado pelas autoras com base nos dados de UN (2001; 2017). 
Nesse sentido, a comparação entre os mandatos da UNAMIR e da UNAMID denota uma diferença relevante: enquanto a UNAMIR é uma missão de paz tradicional, com mandato sob o Capítulo VI, a UNAMID assenta-se no Capítulo VII, sendo uma missão mais robusta. Para Waal (2007), tanto o aprendizado com o genocídio ruandês quanto o número de fatalidades de integrantes da missão em Ruanda (Tabela 1) contribuíram para a formulação do mandato da UNAMID sob o Capítulo VII.

Com uma presença militar reforçada, as tropas da UNAMID tornaram-se uma ameaça à milícia, resultando em mais confrontos - o que explica o índice alto de fatalidades. A comparaçấo entre as fatalidades da UNAMIR e na UNAMID também deve considerar a duração das missóes: a primeira durou 2 anos e 5 meses, e a segunda está ativa há mais de 11 anos. Sendo assim, a média de mortos por ano em cada missão é de 9 na missão em Ruanda e cerca de 22 em Darfur. No entanto, o índice da UNAMID é relativamente baixo se ponderarmos a quantidade de integrantes (UN, 2001; UNOCC, 2019). Mesmo assim, a morte das tropas em Darfur demonstra a necessidade de atentar mais para a segurança da missão e de investir em equipamentos. Essa questão deve ser considerada, pois alega-se que a morte de militares belgas durante a missão em Ruanda foi fundamental para a continuidade do genocídio naquele país, uma vez que culminou na suspensão temporária da UNAMIR por parte da ONU.
A dimensão da UNAMID e sua complexidade política tornaram-se um entrave, segundo Prinsloo e Niekerk (2017) para a efetividade da missão. O impacto negativo do mandato e da necessidade de divisão de responsabilidades com a UA atrasou e dificultou a tomada de decisões. Para os autores, sendo uma questão de paz e segurança internacionais, mesmo que no caso de uma operação de paz híbrida, a ONU é o órgão que deve liderar o processo e não se subordinar às organizaçôes regionais. Apesar de todas as críticas à UNAMID, um de seus grandes legados é a tentativa, ao menos, de incorporar características regionais.

\section{Conclusão}

Compreende-se que as missóes híbridas seriam um meio termo entre o intervencionismo ocidental exagerado na África e a completa ausência de iniciativas para solucionar conflitos críticos locais. Trata-se de um mecanismo que permite a resolução de problemas pelos próprios africanos com a supervisão e o financiamento necessário da ONU. Por outro lado, o fato de ambos os casos estudados se tratarem de genocídios ocorridos mesmo com a presença de missóes de paz naqueles locais revela a falta de eficiência na prevençáo e descontinuação desses crimes, independente da composição dessas operações de paz.

Tabela 1 - Fatalidades UNAMIR e UNAMID

\begin{tabular}{c|c|c}
\hline & UNAMIR & UNAMID \\
\hline Observadores militares & 3 & 1 \\
\hline Tropas & 22 & 58 \\
\hline Polícia cicil & 1 & 29 \\
\hline Equipe local & 1 & 8 \\
\hline Civis internacionais & - & 4 \\
\hline Outros & - & 270 \\
\hline Total & 27 & 270 \\
\hline
\end{tabular}

Fonte: Elaborado pelas autoras com base nos dados de UN (2001) e UNOCC (2019). 
De acordo com o apresentado, a UNAMIR e a UNAMID falharam em diversos aspectos e, a princípio, não foi o suposto caráter africano que fez a missão em Darfur ter mais ou menos sucesso em alcançar seus objetivos em comparação com a missão em Ruanda. Não foram encontradas evidências suficientes neste estudo para comprovar a existência do tal caráter africano, mencionado pela $\mathrm{ONU}$ e conferido à missão híbrida UNAMID, tampouco alguma prova de que a condução da operação tenha sido afetada por sua composiçáo. Inclusive, em 2017, a UNAMID tinha menos componentes africanos do que a UNAMIR teve. Verificou-se que ambas as missōes só avançaram quando houve pressão da comunidade internacional e interesse dos membros permanentes do CSNU. Isso aponta que o discurso de privilegiar a participação de africanos representa uma forma de legitimaçâo das missôes de paz na África, e não a incorporação de variáveis e atores locais para a efetiva resolução de conflitos.

\section{Referências}

ABOAGYE, F. The hybrid operation for Darfur: a critical review of the concept of the mechanism. Institute for Security Studies Papers, Pretoria, n. 149, p. 1-24, 2007.

AFRICAN UNION PSC. Report of the Chairperson of the Commission on the Situation in the Sudan (Crisis in Darfur). Fifth session - 13 April 2004. Addis Ababa: African Union Peace and Security Council, 2004.

AFRICAN UNION. Constitutive Act of African Union. Lomé: African Union, 2000.

BADESCU, C. G.; BERGHOLM, L. The responsibility to protect and the conflict in Darfur: The big let-down. Security Dialogue, v. 40, n. 3, p. 287-309, 2009.

BARROS, C.; MORAIS, C.; DAHER, R. As Peacekeeping Operations (PKOS) e o caso de Ruanda. Fronteira, Belo Horizonte, v. 7, n. 14, p. 47-63, 2008.

BELLAMY, A. J. Responsibility to protect or Trojan horse? The crisis in Darfur and humanitarian intervention after Iraq. Ethics \& International Affairs, New York, v. 19, n. 2, p. 31-54, 2005. GOWAN, R.; JOHNSTONE, I. New Challenges for Peacekeeping: Protection, Peacebuilding, and the" war on Terror". New York: International Peace Academy, 2007.
HEHIR, A. Humanitarian intervention after Kosovo: Iraq, Darfur and the record of global civil society. London: Palgrave Macmillan, 2008.

HUDSON, H. Peacekeeping Trends and Their Gender Implications for Regional Peacekeeping Forces in Africa: Progress and Challenges. In: MAZURANA, D.; RAVEN-ROBERTS, A.; PARPART, J. (Ed.). Gender, Conflict and Peacekeeping. Oxford: Rowman \& Littlefield Publishers, 2005.

KENKEL, K. M. Five generations of peace operations: from the "thin blue line" to "painting a country blue". Revista Brasileira de Política Internacional, Rio de Janeiro, v. 56, n. 1, p. 122-143, 2013.

KREPS, S. E. The United Nations-African Union Mission in Darfur: Implications and prospects for success. African Security Studies, v. 16, n. 4, p. 65-79, 2007.

KUPERMAN, A. J. The limits of humanitarian intervention: Genocide in Rwanda. Washington D.C.: Brookings Institution Press, 2004.

LOPES, D. B. A ONU tem autoridade? Um exercício de contabilidade política (1945-2006). Revista Brasileira de Política Internacional, Rio de Janeiro, v. 50, n. 1, p. 47-65, 2007.

MAKINDA, S. M.; OKUMU, F. W. The African Union: challenges of globalization, security, and governance. New York: Routledge, 2007.

MCQUEEN, C. Humanitarian Intervention and Safety Zones: Iraq, Bosnia, and Rwanda. New York: Palgrave Macmillan, 2005.

MOGHALU, K. Rwanda's genocide: the politics of global justice. New York: Palgrave Macmillan, 2005.

MURITHI, T. The African Union's evolving role in peace operations: the African Union Mission in Burundi, the African Union Mission in Sudan and the African Union Mission in Somalia. African Security Studies, v. 17, n. 1, p. 69-82, 2008. MYINT-U, T.; SCOTT, A. The UN Secretariat: a brief history, 1945-2006. New York: International Peace Academy, 2007.

OTHIENO, T.; SAMASUWO, N. A critical analysis of Africa's experiments with hybrid missions and security collaboration. African Security Studies, v. 16, n. 3, p. 25-39, 2007.

POTI. Core Pre-deployment Training Materials. Williamsburg: Peace Operations Training Institute (POTI), mar. 2014. Disponível em: <https://www.peaceopstraining.org/courses/ core-pre-deployment-training-materials/>. Acesso em: 05 jun. 2018.

PRINSLOO, B.; NIEKERK, D. V. Hybrid peacekeeping and the United Nations: the case of UNAMID. Politikon, v. 44, n. 3, p. 404-424, 2017.

REZENDE, L. P. O engajamento do Brasil nas Operaçóes de Paz da ONU: Análise dos efetivos enviados e recomendaçôes para o fortalecimento da inserçâo internacional brasileira. Curitiba: Appris, 2012. 
UN. UN Mission's Contributions by Country - 28 fev. 2017. [S.1.]: Peace and Security Section of Department of Public Information, 2017. Disponível em: <https://peacekeeping.un.org/ sites/default/files/feb17_5.pdf>. Acesso em: 20 mar. 2019.

UN. UN Mission's Contributions by Country - 31 oct. 2014. [S.1.]: Peace and Security Section of Department of Public Information, 2014. Disponível em: <https://peacekeeping.un.org/ sites/default/files/oct14_3.pdf>. Acesso em: 20 mar. 2019.

UN. UNAMIR - United Nations Assistence Mission for Rwanda (October 1993 - March 1996). [S.1.]: Peace and Security Section of Department of Public Information, 2001. Disponível em: <http://www.un.org/en/peacekeeping/missions/past/unamir.htm>. Acesso em: $20 \mathrm{dez} .2015$.

UNGA. Budget for the African Union-United Nations Hybrid Operation in Darfur for the period from 1 July 2014 to 30 June 2015. Report of the Secretary General. A/68/754. New York: United Nations General Assembly, 2014. Disponível em < https://digitallibrary.un.org/record/769324/files/A_68_754-EN.pdf>. Acesso em 25 mar. 2019.

UNGA. Convention on the Prevention and Punishment of the Crime of Genocide. Adopted by the General Assembly of the United Nations on 9 December 1948. No. 1021. New York: United Nations, 1951. Disponível em: <https://www. un.org/ruleoflaw/files/AH386.pdf>. Acesso em: 22 mar. 2019.

UNGA. Implementation of General Assembly resolutions $\mathbf{5 5 / 2 3 5}$ and 55/236. Report of the Secretary-General. Adopted by the General Assembly at its 70th session, on 28 December 2015. New York: United Nations, 2015. Disponível em: <http:// undocs.org/en/a/70/331/Add.1>. Acesso em: 21 mar. 2019.

UNOCC. Fatalities by Mission and Appointment Type. [S.I]: United Nations Operations and Crisis Centre, 2019. Disponível em: <https://peacekeeping.un.org/sites/default/files/statsbymissionappointmenttype_3_20.pdf>. Acesso em: 17 mar. 2019.

UNP. Ranking of contributors by country (as of 31 December 2018). [S.1]: United Nations Peacekeeping, Troop and police contributors, By Country, 31 dez. 2018. Disponível em: $<$ https://peacekeeping.un.org/en/troop-and-police-contributors $>$. Acesso em: 21 mar. 2019.

UNSC. Report of the Secretary-General on the Sudan - 31 January 2005. New York: United Nations, 2005. Disponível em: <https://undocs.org/S/2005/57>. Acesso em: 22 mar. 2019.

UNSC. Resolution 846 (1993) - Adopted by the Security Council at its 3244th meeting, on 22 June 1993. New York: United Nations, 1993. Disponível em: <https://undocs.org/S/ RES/846(1993)>. Acesso em: 24 mar. 2019.

UNSC. Resolution 1547 (2004) - Adopted by the Security Council at its 4988th meeting, on 11 June 2004. New York: United Nations, 2004. Disponível em: <https://undocs.org/S/ RES/1547(2004)>. Acesso em: 24 mar. 2019.

UNSC. Resolution 1706 (2006) - Adopted by the Security Council at its 5519th meeting, on 31 August 2006. New York: United Nations, 2006. Disponível em: <https://undocs.org/S/ RES/1706(2006)>. Acesso em: 24 mar. 2019.

UNSC. Resolution 1769 (2007) - Adopted by the Security Council at its 5727th meeting, on 31 July 2007. New York: United Nations, 2007. Disponível em: <https://undocs.org/S/ RES/1769(2007)>. Acesso em: 24 mar. 2019.

WAAL, A. Darfur and the failure of the responsibility to protect. International Affairs, v. 83, n. 6, p. 1039-1054, 2007.

WALLIS, J. et al. Hybridity on the Ground in Peacebuilding and Development: Critical Conversations. Canberra: ANU Press, 2018. 